\title{
The Healthy Weights Initiative: results from the first 2,000 participants
}

This article was published in the following Dove Press journal:

Patient Preference and Adherence

\section{Mark Lemstra ${ }^{1,2}$ \\ Yelena Bird ${ }^{3}$ \\ Jeff Fox ${ }^{4}$ \\ John Moraros ${ }^{3}$}

'Alliance Health Medical Clinic, Moose Jaw, SK, Canada; ${ }^{2}$ Alliance Health Medical Clinic, Regina, SK, Canada;

${ }^{3}$ School of Public Health, University of Saskatchewan, Saskatoon, SK, Canada; ${ }^{4}$ YMCA of Moose Jaw, Moose Jaw, SK, Canada
Correspondence: Mark Lemstra Alliance Health Medical Clinic, B70 500-Ist Avenue North West Moose Jaw, SK S6H 8CI, Canada Email marklemstra@shaw.ca
Background: A free, comprehensive, adult obesity reduction program was initiated in the cities of Moose Jaw and Regina, Saskatchewan, Canada.

Objective: This study aimed to determine the short-term and long-term adherence outcomes, identify factors that impact long-term adherence, and measure health outcomes.

Methods: The Healthy Weights Initiative (HWI) attendance was determined by using an electronic swipe card. An on-site exercise therapist also documented physical activity, duration, and intensity, as well as attendance of dietary and cognitive behavioral therapy education classes. Logistic regression determined which factors were associated with long-term adherence (exercising three times per week at 1 year) and various health outcomes.

Results: In this study, 2,167 participants started and 2,000 completed the 24-week program (92.3\%). Upon 24-week completion, the majority of the participants in Moose Jaw $(59.0 \%)$ and Regina (63.1\%) purchased 1-year fitness memberships at the YMCA. At 1 year, 79.8\% of the participants were exercising three times a week or more at the Moose Jaw YMCA. Logistic regression revealed that participants who did not exercise three times a week at 1 year at the YMCA were more likely to have a spouse/partner who did not support the program $(\mathrm{OR}=2.01 ; 95 \% \mathrm{CI}=1.81-2.22)$ and more likely to have a medical comorbidity $(\mathrm{OR}=1.22$; $95 \% \mathrm{CI}=1.03-1.49)$. At 24 weeks, average weight loss was modest (12.7 pounds) and regressed slightly at 1 year (10.4 pounds). However, at 24 weeks, many health gains were statistically significant and were maintained for 1 year. For example, the prevalence of depressed mood reduced from $49.0 \%$ at baseline to $13.0 \%$ at 24 weeks and increased to $19.0 \%$ at 1 year $(P=0.000)$.

Conclusion: We found that the availability of a community-based weight management program (Healthy Weights Initiative) demonstrated good adherence, modest weight loss, and positive health outcomes.

Keywords: obesity, community-based intervention, social support, program adherence

\section{Introduction}

In Canada, as well as the rest of the developed world, the high rates of obesity $(18.3 \%$ in 2011 in Canadian adults) and its deleterious health consequences pose a serious public health concern. ${ }^{1-3}$ A systematic review of the literature found positive associations between obesity and the incidence and prevalence of type 2 diabetes, asthma, osteoarthritis, chronic back pain, several types of cancers, and cardiovascular disease. ${ }^{4}$ The direct costs of being overweight or obese in Canada totaled six billion dollars or $4.1 \%$ of the total health care expenditures in $2006 .{ }^{5}$

In Canada and the developed world, a common pattern is emerging whereby the prevalence of obesity is steadily increasing every year for adults. ${ }^{6}$ To address this issue, a national strategy on healthy living and prevention of chronic diseases was developed. ${ }^{7}$ Despite increased public awareness on the topic, very little research has been done 
about the effectiveness of community-based, weight management programs available to Canadian adults. In the absence of evidence-based research, it is perhaps not surprising that there is a lack of adequate corresponding public policy to help effectively address this complex health care issue.

A new report by the Canadian Obesity Network is warning that Canada is falling short on offering its population access to obesity treatment. The organization reported a grim outlook for Canadians, giving every province across the country failing grades toward adequately helping those with obesity. ${ }^{8}$ According to Statistics Canada, the province with the highest obesity rates is Saskatchewan (the location of the current study), with nearly half of its adult population falling into that category (45.9\%). Particularly concerning, is the fact that Saskatchewan's obesity rates have significantly increased in the last decade and sharply grew from $30.8 \%$ in 2004 to $45.9 \%$ in $2015 .{ }^{9}$

In response, the city of Moose Jaw, Saskatchewan, led 153 community consultations and then initiated a free, comprehensive, adult obesity reduction program titled the Healthy Weights Initiative (HWI). The program commenced with a pilot study on January 1, 2014. During the pilot study, it was learned that having a "buddy" to attend with, and signing social support contracts with three family members and/or friends, were important to improving program adherence. ${ }^{10}$ As such, these two components went from being recommended in the pilot to becoming mandatory in the program. The official HWI program began in Moose Jaw in June of 2015 and then expanded to Regina on February 2016. Both programs occur at the local YMCA.

The present study had three main objectives: 1) to determine adherence levels of 2,000 HWI participants in the short term (24 weeks) and 1,500 participants in the long term (1-year follow-up data were only available for 1,500 at time of publication), 2) to identify factors associated with long-term adherence (1-year post-program completion), and 3) to measure the impact of HWI participation on numerous health outcomes both short-term (24 weeks) and long-term (1 year).

\section{Methods}

\section{Participants}

This study included participants who had a body mass index (BMI) of $30 \mathrm{~kg} / \mathrm{m}^{2}$ or higher and were 18 years old or older. As well, each person needed to receive a medical referral from their own family doctor to ensure it was safe for them to participate (no active recruitment). There were no other inclusion or exclusion criteria. Participation was voluntary and there were no direct or indirect costs to the program. Demographic questions came from the Canadian Comprehensive Health Survey (CCHS) administered by Statistics Canada. ${ }^{10}$

\section{HWI intervention}

There are six main components to the HWI program including: a) the ten population-based recommendations of the Obesity Task Force, b) 72 supervised physical activity sessions with an exercise therapist starting at 20 minutes of aerobic activity at $50 \% \mathrm{VO} 2$ max and progressing to 60 minutes at $80 \%$ VO2 max 5 days a week, c) 12 group dietary education sessions focusing on reducing caloric intake and following the Canada Food Guide, d) 12 cognitive behavior therapy education sessions to help participants initiate and maintain complex behavioral change, e) attending all exercise and education sessions with a "buddy" of the participants' choice, and f) signing social support contracts with an additional three family members and/or friends. ${ }^{10}$

\section{Outcomes}

A wide array of health outcomes were determined for each participant at baseline and then again at 12 weeks, 24 weeks, and 1 year. These measurements included weight, height, BMI, waist and hip, percentage body fat (Durnin-Wormersley method advocated by Canadian Society of Exercise Physiology), blood pressure, blood cholesterol, blood glucose, aerobic fitness (Canadian Aerobic Fitness Test), depressed mood (score of 11 or higher on Beck Depression Inventory [BDI]-2), health-related quality of life (Short Form-36), musculoskeletal pain (average from 1 or lowest to 10 or maximal pain), self-reported comorbidity, and various outcomes from the CCHS, including self-reported health, mental health, dietary consumption, smoking prevalence, and health care utilization. ${ }^{11-16}$ Blood cholesterol and blood glucose measurements were taken by the Saskatchewan Health Authority and followed their protocols.

The program components, and the outcome measures, are explained in great detail in a previous publication that discussed short-term results of a small sample of participants. ${ }^{10}$

Program attendance was determined by the electronic swipe card required by the YMCA to enter their facilities. Program adherence was determined by the on-site exercise therapist who documented attendance or frequency, physical activity, duration, and intensity, and attendance of dietary and cognitive behavior therapy education classes (knowledge translation was not monitored-only attendance). After completing the program, and after purchasing a regular cost 
membership at the YMCA, long-term program adherence for HWI participants was defined and assessed as exercising three times a week or more at 1 year.

\section{Statistics}

An SPSS 22 statistical package was used to compare mean scores from baseline to 24-week follow-up, and baseline to 1-year follow-up, with paired sample $t$-tests. Logistic regression analysis was used to determine which factors were associated with long-term adherence (exercising three times per week at 1 year) and health outcomes (including weight loss, aerobic fitness, depressed mood, and health-related quality of life).

\section{Ethics}

All participants provided written informed consent for the community-based program and evaluation occurring at the local YMCA. A full ethics submission was submitted to the Behavioral Research Ethics Board of the University of Saskatchewan. According to university policy, article 2.5 of the Tri Council Policy Statement, research with minimal risk with a focus on program evaluation can be granted an exemption from full ethical review, including the publication of de-identified data. As such, the Behavioral Ethics Board of the University of Saskatchewan granted an exemption to this research proposal on January 29, 2015 (BEH-15-28).

\section{Results}

The demographic results of the participants are presented in Table $1(\mathrm{~N}=2,000)$. The demographic characteristics of the study population were consistent with provincial averages for Saskatchewan with the exception of gender, whereby HWI participation and completion were much higher among females (79\%) than males (21\%). In comparison, Statistics Canada reports that $48 \%$ of Saskatchewan adult residents are female and $52 \%$ are male. ${ }^{1}$

From June 2015 to February 2018, 2,167 participants started and 2,000 (1,000 in Moose Jaw and 1,000 in Regina) completed the 24-week HWI program (92.3\%) as monitored by electronic swipe cards. The on-site exercise therapist documented physical activity and dietary and cognitive behavior therapy education class attendance. The therapist reported that average activity attendance was 62/72 (86.1\%), average dietary education attendance was 11/12 (91.7\%), and cognitive behavior therapy education attendance was $10 / 12$ or $83.3 \%$. Upon 24-week completion, $59 \%$ (590 out of 1,000 ) of the participants in Moose Jaw and 63.1\% (631 out of 1,000)
Table I Demographics of first 2,000 Healthy Weights Initiative (HWI) participants who completed the 24-week HWI in Moose Jaw and Regina, Saskatchewan, Canada

\begin{tabular}{ll}
\hline Demographics & (\%) (SD) \\
\hline Gender & \\
Males & 21.0 \\
Females & 79.0 \\
Age (years) & \\
65+ & 3.0 \\
$55-64$ & 25.0 \\
$45-54$ & 26.0 \\
$35-44$ & 33.0 \\
$26-34$ & 11.0 \\
I8-25 & 2.0 \\
Mean age (years) & $43.2(3.1)$ \\
Marital status & \\
Married/common-law & 69.0 \\
Single & 31.0 \\
Employment & \\
Not employed (includes students) & 21.0 \\
Non-professional & 56.0 \\
Professional & 23.0 \\
Education level & \\
< High school graduate & 6.0 \\
High school graduate & 38.0 \\
College/tech/trades & 40.0 \\
University & 16.0 \\
Medical comorbidities (self-reported) & \\
None & 19.0 \\
I & 41.0 \\
3 or more & 22.0 \\
\hline & 18.0 \\
\hline &
\end{tabular}

in Regina purchased 1-year fitness memberships at the YMCA as determined by contractual sales (Figure 1).

After purchasing a membership at the YMCA, long-term program adherence for HWI participants was defined and assessed as exercising three times a week or more at 1 year. Presently, information on this variable is only available for the Moose Jaw YMCA. It was found that at 1 year, $79.8 \%$ of the members who purchased memberships were still exercising three times a week or more (471 out of 590). That said, among all 1,000 participants who completed the 24-week HWI program, only $47.1 \%$ (471 out of 1,000) purchased a membership and had long-term adherence at the Moose Jaw YMCA (Figure 1).

Prior to logistic regression analysis, the study sample was stratified into two groups. Logistic regression was used to determine the independent association between the outcome variable of a) completing the 24-week program, purchasing a membership at the YMCA, and exercising three times per week or more at 1 year $(\mathrm{N}=471)$ and $b)$ completing the 24-week program, purchasing or not purchasing a 


\section{2,167 participants started \\ 2,000 participants completed $(92.3 \%)$}

Moose Jaw (1,000 completed)

590 (59.0\%) bought long-term membership

471 exercising three times a week or more at 1 year $(79.8 \%)$
Regina (1,000 completed)

631 (63.1\%) bought long-term membership

Data not available

Figure I Participant adherence flow chart.

membership at the Moose Jaw YMCA, and not exercising three times a week at 1 year $(\mathrm{N}=529)$ at the Moose Jaw YMCA.

Using logistic regression, non-adherence at 1 year (529 to 471 participants) was associated with not having a spouse/partner actively supporting the program $(\mathrm{OR}=2.01$; 95\% CI=1.81-2.22) and having a self-reported medical comorbidity $(\mathrm{OR}=1.22 ; 95 \% \mathrm{CI}=1.03-1.49)$ with osteoarthritis of the knee being the most common complaint.

The HWI participant health outcomes as determined at baseline, 24 weeks ( $N=2,000$ participants), and 1 year
$(\mathrm{N}=1,500$ participants because 1 -year data were only available on 1,500) of the HWI program are presented in Table 2. Statistically significant differences were noted at 24 weeks and at 1 year for changes in weight, waist measurement, hip measurement, BMI, percentage body fat, systolic blood pressure, blood cholesterol, aerobic fitness, depressed mood, health-related quality of life, self-reported health, selfreported mental health, musculoskeletal pain (average pain), dietary consumption (fruit, vegetables, fast food, soft drinks), smoking status, and health care utilization (self-reported physician visits, hospital visits, and medication use).

Table 2 Health differences among those who completed Healthy Weights Initiative (HWI) at 24 weeks post-completion (2,000 participants) and I year post-completion (I,500 participants)

\begin{tabular}{|c|c|c|c|c|}
\hline Physiological changes & $\begin{array}{l}\text { Pre-HWI } \\
\text { mean (SD) }\end{array}$ & $\begin{array}{l}24 \text { weeks post- } \\
\text { HWI mean (SD) }\end{array}$ & $\begin{array}{l}\text { I year post- } \\
\text { HWI mean (SD) }\end{array}$ & $\begin{array}{l}\text { Significance } \\
\text { (baseline - I year) }\end{array}$ \\
\hline Weight (pounds) & $241.8(46.6)$ & $229.1(43.8)$ & $231.4(43.6)$ & 0.005 \\
\hline Body mass index, $\mathrm{kg} / \mathrm{m}^{2}$ & $38.1(6.8)$ & $36.1(6.1)$ & $36.9(6.9)$ & 0.021 \\
\hline Fat (pounds) & I05.I (26.2) & $91.5(26.6)$ & $92.4(27.2)$ & 0.000 \\
\hline Body fat (\%) & $49.1(4.2)$ & $44.1(4.9)$ & $44.8(4.8)$ & 0.000 \\
\hline Waist circumference, inch & $45.1(5.6)$ & $42.1(5.1)$ & $42.9(5.5)$ & 0.039 \\
\hline Hip circumference, inch & $51.6(6.6)$ & $48.9(5.9)$ & $49.8(6.1)$ & 0.031 \\
\hline Systolic blood pressure, mmHG & $130.4(14.2)$ & $125.5(9.1)$ & $126.5(9.3)$ & 0.004 \\
\hline Diastolic blood pressure, $\mathrm{mmHG}$ & $82.7(11.8)$ & $80.4(8.7)$ & $82.3(8.8)$ & 0.059 \\
\hline Blood glucose, mmoL & $5.8(1.9)$ & $5.7(1.3)$ & $5.8(1.4)$ & 0.899 \\
\hline Blood cholesterol, mmoL & $4.8(1.2)$ & $4.4(1.0)$ & $4.4(1.1)$ & 0.045 \\
\hline CAFT aerobic fitness & $122.5(107.1)$ & $182.0(|| 5.2)$ & $169.1(121.3)$ & 0.019 \\
\hline Minutes hard PA/week & $42.4(21.1)$ & $160.0(63.2)$ & $108.1(36.6)$ & 0.000 \\
\hline Minutes moderate PA/week & $78.6(3 \mid .2)$ & $150.5(53.1)$ & $145.3(47.1)$ & 0.000 \\
\hline MSK pain score (average I-10) & $3.9 / 10(0.4)$ & $2.1 / 10(0.5)$ & $2.1 / 10(0.5)$ & 0.009 \\
\hline $\begin{array}{l}\text { Health-related } \\
\text { quality of life (Short Form-36) }\end{array}$ & $\begin{array}{l}\text { Pre-HWI } \\
\text { mean (SD) }\end{array}$ & $\begin{array}{l}24 \text { weeks post- } \\
\text { HWI mean (SD) }\end{array}$ & $\begin{array}{l}\text { I year post- } \\
\text { HWI mean (SD) }\end{array}$ & $\begin{array}{l}\text { Significance } \\
\text { (baseline - I year) }\end{array}$ \\
\hline Physical functioning & $59.0(20.1)$ & $72.7(20.7)$ & $69.3(20.3)$ & 0.000 \\
\hline Limits - physical & $69.9(30.3)$ & $54.3(27.1)$ & $57.9(32.3)$ & 0.000 \\
\hline Pain & $67.1(21.9)$ & $53.9(17.1)$ & $55.8(18.1)$ & 0.000 \\
\hline General health & $46.8(18.2)$ & $70.5(19.0)$ & $68.7(19.5)$ & 0.000 \\
\hline Vitality & $42.1(16.1)$ & $59.9(17.3)$ & $58.5(17.4)$ & 0.000 \\
\hline Social functioning & $61.1(21.7)$ & $78.1(21.8)$ & 7I.I (2I.5) & 0.000 \\
\hline Limits - emotional & $71.4(29.8)$ & $50.5(27.7)$ & $52.1(27.7)$ & 0.000 \\
\hline Emotional well-being & $57.8(\mid 7.2)$ & $77.6(18.4)$ & $78.2(19.1)$ & 0.000 \\
\hline Physical composite score & $44.7(8.2)$ & $57.9(8.1)$ & $57.0(8.0)$ & 0.000 \\
\hline Mental composite score & $48.3(10.4)$ & $60.2(8.0)$ & $60.2(8.1)$ & 0.000 \\
\hline
\end{tabular}


Table 2 (Continued)

\begin{tabular}{|c|c|c|c|c|}
\hline $\begin{array}{l}\text { Depressed mood } \\
\text { (Beck Depression Inventory } \\
[B D I]-2)\end{array}$ & $\begin{array}{l}\text { Pre-HWI } \\
\text { mean (SD) }\end{array}$ & $\begin{array}{l}24 \text { weeks post- } \\
\text { HWI mean (SD) }\end{array}$ & $\begin{array}{l}\text { I year post- } \\
\text { HWI mean (SD) }\end{array}$ & $\begin{array}{l}\text { Significance } \\
\text { (baseline - I year) }\end{array}$ \\
\hline \multirow[t]{2}{*}{ BDI-2 score - mean (SD) } & I I.7 (7.3) & $4.3(3.1)$ & $4.5(3.7)$ & 0.000 \\
\hline & Pre-HWI & HWI 24 weeks & HWI I year & \\
\hline Severe/extreme $(3 I+)$ & $2.0 \%$ & $3.0 \%$ & $2.0 \%$ & \\
\hline Moderate $(2 \mid-30)$ & $9.0 \%$ & $4.0 \%$ & $4.0 \%$ & \\
\hline Borderline (I7-20) & $15.0 \%$ & $5.0 \%$ & $6.0 \%$ & \\
\hline Mild (II-I6) & $23.0 \%$ & $2.0 \%$ & $7.0 \%$ & \\
\hline No depressed mood & $51.0 \%$ & $87.0 \%$ & $81.0 \%$ & \\
\hline Depressed mood $(\mathrm{II}+)$ & $49.0 \%$ & $13.0 \%$ & $19.0 \%$ & \\
\hline $\begin{array}{l}\text { Self-reported health } \\
\text { (Canadian Comprehensive } \\
\text { Health Survey [CCHS]) }\end{array}$ & Pre-HWI (\%) & $\begin{array}{l}\text { HWI } 24 \text { weeks } \\
\text { (\%) }\end{array}$ & HWI I year (\%) & 0.000 \\
\hline Poor & $19.0 \%$ & $3.0 \%$ & $7.0 \%$ & \\
\hline Fair & $41.0 \%$ & $16.0 \%$ & $23.0 \%$ & \\
\hline Good & $29.0 \%$ & $52.0 \%$ & $41.0 \%$ & \\
\hline Very good/excellent & $\mathrm{II} .0 \%$ & $29.0 \%$ & $29.0 \%$ & \\
\hline $\begin{array}{l}\text { Self-reported mental health } \\
\text { (CCHS) }\end{array}$ & $\begin{array}{l}\text { Pre-HWI } \\
\text { (\%) }\end{array}$ & $\begin{array}{l}\text { HWI } 24 \text { weeks } \\
\text { (\%) }\end{array}$ & $\begin{array}{l}\text { HWI I year } \\
\text { (\%) }\end{array}$ & 0.000 \\
\hline Poor & $1 \mathrm{I} .0 \%$ & $4.0 \%$ & $5.0 \%$ & \\
\hline Fair & $23.0 \%$ & $9.0 \%$ & $14.0 \%$ & \\
\hline Good & $39.0 \%$ & $41.0 \%$ & $39.0 \%$ & \\
\hline Very good/excellent & $27.0 \%$ & $46.0 \%$ & $42.0 \%$ & \\
\hline $\begin{array}{l}\text { Self-reported health care } \\
\text { utilization (CCHS) }\end{array}$ & Pre-HWI & HWI 24 weeks & HWI I year & \\
\hline Doctor visits (mean, SD) & $\mathrm{I} .7(0.3)$ & $0.9(0.4)$ & $0.9(0.4)$ & 0.004 \\
\hline Hospitalizations & (\%) & (\%) & (\%) & 0.040 \\
\hline 0 & $69.0 \%$ & $90.0 \%$ & $85.0 \%$ & \\
\hline I & $16.0 \%$ & $5.0 \%$ & $13.0 \%$ & \\
\hline 2 & $12.0 \%$ & $5.0 \%$ & $1.0 \%$ & \\
\hline 3 or more & $3.0 \%$ & $0.0 \%$ & $1.0 \%$ & \\
\hline Medications (mean, SD) & $\mathrm{I} .8(0.4)$ & $\mathrm{I} .0(032)$ & $\mathrm{I} .0(0.3)$ & 0.049 \\
\hline $\begin{array}{l}\text { Self-reported smoking } \\
\text { (CCHS) }\end{array}$ & Pre-HWI & HWI 24 weeks & HWI I year & 0.000 \\
\hline Daily smoker & $19.0 \%$ & $9.0 \%$ & $8.0 \%$ & \\
\hline $\begin{array}{l}\text { Self-reported dietary } \\
\text { behaviors (consumption per } \\
\text { day - CCHS) }\end{array}$ & $\begin{array}{l}\text { Pre-HWI } \\
\text { mean (SD) }\end{array}$ & $\begin{array}{l}24 \text { weeks post- } \\
\text { HWI mean (SD) }\end{array}$ & $\begin{array}{l}\text { I year post- } \\
\text { HWI mean (SD) }\end{array}$ & $\begin{array}{l}\text { Significance } \\
\text { (baseline - I year) }\end{array}$ \\
\hline Meat & $\mathrm{I} .3(0.7)$ & $\mathrm{I} .3(0.7)$ & $\mathrm{I} .3(0.7)$ & 0.079 \\
\hline Fruit & $\mathrm{I} .2(0.9)$ & $2.3(1.0)$ & $2.5(I .1)$ & 0.000 \\
\hline Vegetables & $1.7(1.1)$ & $2.4(1.0)$ & $2.9(1.1)$ & 0.000 \\
\hline Milk & $0.7(1.0)$ & $0.8(1.0)$ & $0.8(1.0)$ & 0.081 \\
\hline Soft drinks & $0.9(1.1)$ & $0.2(0.6)$ & $0.2(0.6)$ & 0.000 \\
\hline Fast food & $1.7(1.0)$ & $0.7(0.9)$ & $0.4(0.5)$ & 0.000 \\
\hline
\end{tabular}

Abbreviations: CAFT, Canadian Aerobic Fitness Test; PA, physical activity; SK, musculoskeletal.

No statistically significant changes were noted for diastolic blood pressure, blood sugar, or dietary consumption of milk or meat products.

As mentioned previously, long-term (1 year) changes were monitored, including rates of depressed mood. Using the BDI-2, 49.0\% of the participants reported having depressed mood (score of 11 or higher on the survey) before starting the program (ie, baseline). However, at 24 weeks, and then again at 1 year, only $13.0 \%$ and $19.0 \%$ of the study participants, respectively, reported having depressed mood.

\section{Discussion}

Our HWI program provides the first comprehensive approach and assessment of managing obesity in Saskatchewan, Canada. Overall, our research revealed several important findings. Our adherence rates were adequate. During the 
study period, 2,167 participants started and 2,000 completed the 24-week program (92.3\%). Upon the 24-week completion, $59.0 \%$ of the participants in Moose Jaw and $63.1 \%$ in Regina purchased a 1-year fitness membership at the local YMCA. At 1 year, 79.8\% of those who purchased memberships were exercising three times a week or more at the Moose Jaw YMCA. These results are consistent, although higher, than the ones reported in a systematic literature review that found $60.5 \%$ adherence to weight loss programs of varying durations. ${ }^{17}$

Within this systematic literature review, it was found that social support was the most important variable to impact adherence. ${ }^{17}$ Social support is also known to be an important determinant in behavioral modification and overall health. ${ }^{18}$ Given that our HWI program predominately focused on a buddy system for social support, and has three additional family members or friends sign social support contracts, these variables likely help explain the higher than expected adherence outcomes. ${ }^{10}$

Similarly, after logistic regression, it was determined that participants who did not exercise three times a week at 1 year at the YMCA were associated with having a spouse/ partner who did not support the HWI program $(\mathrm{OR}=2.01$; $95 \% \mathrm{CI}=1.81-2.22$ ). It is important to distinguish that although the HWI participants had to attend the sessions with a buddy, and have three social support contracts signed, these social support components did not necessarily include the participants' spouse/partner. As such, a participant could have the odd situation of receiving significant social support from others, but not from their own spouse/partner. Multiple studies have indicated that social support, whether through family, friends, peers, or providers, is an important component to enacting and sustaining successful behavioral change in weight management programs. ${ }^{10,17,19,20}$ However, the specific importance of spousal/partner support, above and beyond that of other family members and friends, has not been adequately investigated. ${ }^{21}$

It is interesting to note that even though an equal opportunity was provided to both genders to enroll into our HWI program, nearly eight-of-ten participants were female. Paradoxically, the literature reports that between the ages of 18 and 54 years old, more men than women are obese in Canada and yet, men are able to lose weight faster and more efficiently than women but somehow get overlooked, as focus remains on women. ${ }^{22,23}$ This may be attributed to a wider social perception that weight management programs are mainly designed for women, which may be related to the use of gender-based advertising and marketing strategies, and the fact that very few programs specifically target men. Additionally, studies have shown that women may be more likely to seek help with their weight than men because they feel more conscious of their body image, embarrassment about their appearance, and pressure to avoid social stigmatization. ${ }^{24-27}$

It is important to note that although a number of statistically significant positive health outcomes were observed at both 24 weeks and at 1 year of our study, many of these changes were modest in nature. As such, their clinical significance remains unclear. For example, actual average weight loss was only 12.7 pounds at 24 weeks and 10.4 pounds at 1 year. This slight regression over time (from 24 weeks to 1 year) was also a common and recurrent finding through most of our study health outcomes. Similar modest changes were observed for waist and hip measurements, BMI, percentage body fat, systolic blood pressure, blood cholesterol, musculoskeletal pain (average pain), dietary consumption (fruit, vegetables, fast food, soft drinks), and health care utilization (self-reported physician visits, hospital visits, and medication use).

That disclosure noted, there were health outcomes that appeared to have statistically significant and possibly clinically relevant changes in both the short term and long term. For example, the prevalence of depressed mood reduced from $49.0 \%$ at baseline to $13.0 \%$ at 24 weeks and only increased to $19.0 \%$ at 1 year. Similar statistically and clinically positive changes were observed on the variables for health-related quality of life, aerobic fitness, self-reported health, selfreported mental health, and smoking status. The literature reports that weight management programs help participants improve their self-esteem, mental well-being, and quality of life. ${ }^{25-32}$ Weight management programs may, therefore, serve to improve these psychological outcomes and, in turn, these improvements may increase the chances of maintaining successful weight loss. ${ }^{25,33}$

The study has a number of strengths and limitations. The most important is that the HWI is a real-world, prospective, observational study and not a randomized controlled trial. Studies should include a suitable control group not receiving treatment or a suitable comparison group, which would permit more reliable inferences about the effects of the intervention. As such, only associations can be determined and not causations. Moreover, it was not possible to calculate the effect size for all the variable comparisons of interest. Consequently, not all observed effects are generalizable and therefore, a number of our findings should be treated with caution. 


\section{Conclusion}

Canada is facing an obesity epidemic. We found that the availability of a free, community-based weight management program (HWI) can have a positive impact in participants' lives by demonstrating adequate adherence, modest weight loss, and a number of positive health outcomes. Additionally, improvements in depressed mood and health-related quality of life were observed. More research is needed to improve the quality of intervention trials, fully elucidate the impact of spousal/partner support, and help identify the marked gender differences in participation in weight management programs. Finally, to enhance the effectiveness and increase the adherence of future weight management programs, it is important to identify the key components that lead to improved physiological and psychological outcomes and, thus, ensure long-term success.

\section{Acknowledgments}

Special thanks to the Moose Jaw YMCA and the Regina YMCA. Partial funding was obtained from the Public Health Agency of Canada (1516-HQ-000036). The views expressed herein do not necessarily represent the views of the Public Health Agency of Canada.

\section{Disclosure}

The authors report no conflicts of interest in this work.

\section{References}

1. Statistics Canada [webpage on the Internet]. Canadian Community Health Survey - Nutrition. Health Canada: Ottawa; 2015. Available from: http:// www23.statcan.gc.ca/imdb/p2SV.pl?Function=getSurvey\&SDDS=5049. Accessed February 9, 2018

2. World Health Organization [webpage on the Internet]. Obesity and Overweight - Factsheet. Geneva, Switzerland; 2018. Available from: http://www.who.int/mediacentre/factsheets/fs311/en/. Accessed February 11, 2018.

3. Statistics Canada [webpage on the Internet]. Obesity in Canada. Health Canada: Ottawa; 2016. Available from: https://www.canada.ca/en/ public-health/services/health-promotion/healthy-living/obesity-canada. html\#toc. Accessed January 11, 2018

4. Hramiak I, Leiter L, Paul TL, Ur E. Assessment of obesity and its complications in adults. CMAJ. 2007;178:36-39.

5. Franz MJ, Vanwormer JJ, Crain AL, et al. Weight-loss outcomes: a systematic review and meta-analysis of weight-loss clinical trials with a minimum 1-year follow-up. J Am Diet Assoc. 2007;107(10):1755-1767.

6. Health Canada [webpage on the Internet]. The Government of Canada Reaffirms Its Commitment to Combat Canada's Rising Obesity Levels. Ottawa: Health Canada; 2005. Available from: https://www.canada.ca/ en/news/archive/2005/07/government-canada-reaffirms-commitmentcombat-canada-rising-obesity-levels.html. Accessed January 1, 2018.

7. Anis AH, Zhang W, Bansback N, Guh DP, Amarsi Z, Birmingham CL. Obesity and overweight in Canada: an updated cost-of-illness study. Obes Rev. 2010;11(1):31-40.
8. Canadian Obesity Network [webpage on the Internet]. Canadians Lack Access to Obesity Treatments and Support: Report Card; 2017. Available from: http://www.obesitynetwork.ca/canadians-lack-accessto-obesity-treatments-and-support-report-card-4-25-2017. Accessed February 21, 2018.

9. Statistics Canada [webpage on the Internet]. Health Indicator Profile, Annual Estimates, by Age Group and Sex, Canada, Provinces, Territories, Health Regions and Peer Groups. Ottawa: Health Canada; 2015. Available from: https://www150.statcan.gc.ca/n1/daily-quotidien/150525/ dq150525c-cansim-eng.htm. Accessed January 1, 2018.

10. Lemstra M, Rogers MR. The importance of community consultation and social support in adhering to an obesity reduction program: results from the Healthy Weights Initiative. Patient Prefer Adherence. 2015;9: 1473-1480.

11. Canadian Society for Exercise Physiology. Physical Activity Training for Health - Resource Manual. Ottawa, ON: Canadian Society for Exercise Physiology; 2013.

12. Canadian Fitness and Lifestyle Research Institute. Physical Activity Monitor. Ottawa, ON: Canadian Fitness and Lifestyle Research Institute; 1995.

13. Canadian Society for Exercise Physiology. The Canadian Physical Activity, Fitness, and Lifestyle Approach (CMAFLA). 3rd ed. Ottawa, ON: Canadian Society for Exercise Physiology; 2003.

14. Beck AT, Steer RA, Brown GK. Manual for the Beck Depression Inventory-II. San Antonio, TX: Psychological Corporation; 1996.

15. Segal DL, Coolidge FL, Cahill BS, O'Riley AA. Psychometric properties of the Beck Depression Inventory II (BDI-II) among communitydwelling older adults. Behav Modif. 2008;32(1):3-20.

16. Ware JE, Kosinski M, Keller SD. SF-36 Physical and Mental Health Summary Scales: A Users ' Manual. Boston, MA: The Health Institute; 1994.

17. Lemstra M, Bird Y, Nwankwo C, Rogers M, Moraros J. Weight loss intervention adherence and factors promoting adherence: a metaanalysis. Patient Prefer Adherence. 2016;10:1547-1559.

18. Public Health Agency of Canada [webpage on the Internet]. What Makes Canadians Healthy or Unhealthy? 2017. Available from: http://www. phac-aspc.gc.ca/ph-sp/determinants/determinants-eng/php. Accessed December 7, 2017.

19. Kumanyika S, Jeffery RW, Morabia A, Ritenbaug C, Antipatis VJ. Public Health Approaches to the Prevention of Obesity (PAHPO) Working Group of the International Obesity Task Force (IOTF). Int $J$ Obesity. 2002;26:425-436.

20. Wing RR, Jeffery RW. Benefits of recruiting participants with friends and increasing social support for weight loss and maintenance. J Consult Clin Psychol. 1999;67(1):132-138.

21. Murphy JK, Williamson DA, Buxton AE, Moody SC, Absher N, Warner M. The long-term effects of spouse involvement upon weight loss and maintenance. Behav Ther. 1982;13(5):681-693.

22. Orpana HM, Tremblay MS, Finès P. Trends in Weight Change among Canadian Adults. Available from: http://www.statcan.gc.ca/pub/82-003x/2006005/article/trends-tendances/9633-eng.pdf. Accessed January 16, 2018.

23. Williams RL, Wood LG, Collins CE, Callister R. Effectiveness of weight loss interventions - is there a difference between men and women: a systematic review. Obes Rev. 2015;16(2):171-186.

24. Palmeira AL, Markland DA, Silva MN, et al. Reciprocal effects among changes in weight, body image, and other psychological factors during behavioral obesity treatment: a mediation analysis. Int J Behav Nutr Phys Act. 2009;6:9.

25. Teixeira PJ, Going SB, Houtkooper LB, et al. Pretreatment predictors of attrition and successful weight management in women. Int $J$ Obes Relat Metab Disord. 2004;28(9):1124-1133.

26. Friedman KE, Reichmann SK, Costanzo PR, Zelli A, Ashmore JA, Musante GJ. Weight stigmatization and ideological beliefs: relation to psychological functioning in obese adults. Obes Res. 2005;13(5):907-916. 
27. Depierre JA, Puhl RM. Experiences of weight stigmatization: a review of self-report assessment measures. Obes Facts. 2012;5(6):897-918.

28. Madan AK, Beech BM, Tichansky DS. Body esteem improves after bariatric surgery. Surg Innov. 2008;15(1):32-37.

29. Faith MS, Fontaine KR, Cheskin LJ, Allison DB. Behavioral approaches to the problems of obesity. Behav Modif. 2000;24(4):459-493.

30. Faulconbridge LF, Wadden TA, Berkowitz RI, et al. Changes in symptoms of depression with weight loss: results of a randomized trial. Obesity. 2009;17(5):1009-1016.
31. Fontaine KR, Barofsky I, Andersen RE, et al. Impact of weight loss on health-related quality of life. Qual Life Res. 1999;8(3):275-277.

32. Blaine BE, Rodman J, Newman JM. Weight loss treatment and psychological well-being: a review and meta-analysis. J Health Psychol. 2007; 12(1):66-82.

33. Rothberg AE, Mcewen LN, Kraftson AT, et al. The impact of weight loss on health-related quality-of-life: implications for cost-effectiveness analyses. Qual Life Res. 2014;23(4):1371-1376.

\section{Publish your work in this journal}

Patient Preference and Adherence is an international, peer-reviewed, open access journal that focuses on the growing importance of patient preference and adherence throughout the therapeutic continuum. Patient satisfaction, acceptability, quality of life, compliance, persistence and their role in developing new therapeutic modalities and compounds to optimize clinical outcomes for existing disease states are major areas of interest for the journal. This journal has been accepted for indexing on PubMed Central. The manuscript management system is completely online and includes a very quick and fair peer-review system, which is all easy to use. Visit http://www. dovepress.com/testimonials.php to read real quotes from published authors.

Submit your manuscript here: http://www.dovepress.com/patient-preference-and-adherence-journal 